\title{
DAMAGE ASSESSMENT OF NATURAL DISASTERS BASED ON CLOUD MODEL
}

\author{
LIU, Y.P. ${ }^{1}-$ GAO, Y.Q. ${ }^{*}-$ CHEN, H.Y. ${ }^{1,2}-$ LAI, L.J. ${ }^{1}$ \\ ${ }^{1}$ College of Water Conservancy and Hydropower Engineering, Hohai University \\ 1 Xikang Road, Nanjing 210098, P. R. China \\ ${ }^{2}$ Nanjing Water Planning and Designing Institute Corp. Ltd \\ 136 Honghuacun Road, Nanjing 210022, P. R. China \\ *Corresponding author \\ e-mail:yqgao@hhu.edu.cn; phone: +86-139-5188-9955 \\ (Received $11^{\text {th }}$ Jan 2019; accepted $8^{\text {th }}$ Mar 2019)
}

\begin{abstract}
Natural disasters occur frequently in China and cause inordinate social and economic losses every year. Great attention has been paid to assessing the impact disasters has brought in order to take appropriate prevention as well as follow-up steps. The existing assessment indexes are not comprehensive and systematic enough to evaluate the disasters' social, economic and environmental impact. Besides, the assessment method and standard are not objective. A more comprehensive natural disaster evaluation index system is proposed and the weight determination and severity rating methods based on cloud model is presented in this paper to provide a reference to appropriately select the assessment method for different kinds of disasters. The index system and severity rating method are applied to 6 typical rainstorms and flood events. Five indicators on social and economic aspects are implemented to demonstrate the adaptability of the proposed method. The results of analysis and evaluation show that the weight set based on cloud model can gather all information from experts objectively, and the assessment method can achieve a reasonable standard of disaster grades reasonably and determine the grade level objectively.
\end{abstract}

Keywords: evaluation of natural disaster situation, evaluation index system, weight determination method, disaster identification degree, rainstorm flooding

\section{Introduction}

Natural disasters have an adverse impact on personal safety, agriculture, industry, society, economic and ecological environment. For example, in China, 190 million natural disaster victims were recorded in 2016, 1706 dead or missing, 9.1 million people needed emergency resettlement, 521,000 houses collapsed, 3.34 million houses were damaged, the affected area of crops reached 26220.7 thousand hectares, and the proportion of crop failure or death was 2902.2 thousand hectares. Direct economic losses amounted to 503.29 billion yuan (Liu et al., 2017). In recent years, vulnerability of China's natural environment has been increasing, ecological and environmental issues have become prominent, and natural disasters have been frequent and highintensity. With the continuous growth of urbanization level and the development of social productive forces, population density continues to rise, economic aggregates and density increase rapidly, inter-regional economic linkages and cooperation increase, disaster prevention and rescue measures continue to improve, and economic losses and society caused by disasters The impact is constantly increasing. The characteristics of disaster losses are also changing: the number of deaths due to disasters has dropped, the number of people affected has risen, and direct and indirect economic losses have risen sharply. According to statistics, the average annual disaster loss in China since the 
1990s is $40 \%$ higher than in the 1980s (Tang and $\mathrm{Yu}, 2016$ ). In order to objectively and comprehensively reflect the damage severity and loss characteristics of natural disasters, and provide the basis for defensive measures optimization and disaster mitigation strategies, it is of absolute necessity to conduct disaster evaluation study.

At present, there have been numerous studies on disaster damage assessment such as floods, typhoons, storm surges and geological disasters. For example, Yang et al. (2010) selected indicators such as the number of death, the number of people affected, the number of collapsed houses, the area affected by crops, and the direct economic loss. The entropy method was used to calculate the weight, and the flood damage in 22 regions of China was evaluated in 1999. Gong et al. (2015) took 25 factors in disaster factors, disaster-bearing bodies and disaster prevention and mitigation capabilities with the number of deaths, the number of collapsed houses, the area affected by crops, the direct economic loss and the disaster index to conduct correlation analysis and studied the index selection of typhoon disaster damage assessment. Yin et al. (2012) established an index system from the aspects of casualties, fisheries and agriculture, and direct economic losses of living facilities, and applied the analytic hierarchy process and entropy method to determine the weights and assess the economic losses of 7 storm surge disasters in Guangdong Province. Cheng et al. (2011) selected the average earthquake intensity, the number of deaths missing, the death and disappearance rate of 10,000 people, the number of collapsed houses, the rate of collapsed houses, the risk of geological disasters, and the resettlement rate of 10,000 people to conduct county-wise grade evaluation of disasters in the earthquake-stricken areas; Shi et al. (2017) constructed the economic loss indicators and risk indicators for disaster relief based on the affected area of the disaster, the area planted with crops, the total production value and the frequency of disaster relief by the county of Xinjiang Statistics from 1984 to 2014, to assess the hail disaster in Xinjiang. In addition, the Ministry of Water Resources approved the Flood Disaster Assessment Standard (Standard) in 2012, mainly selecting the number of deaths, the number of people affected, the area affected by crops, the number of collapsed houses, the direct economic loss, and the economic loss of water conservancy facilities as a direct economic loss. Such indicators are employed to the assessment of the number of events and regional annual floods.

There are some shortcomings in the above research. The indicators selected for the disaster damage assessment are not comprehensive enough: only the agricultural impact is considered, the influence of industry and the tertiary industry is neglected; the socioeconomic impact is considered, and the natural environmental impact is not considered; The indicators are scattered, without a comprehensive and systematic evaluation index system; At present, China's official disaster information reporting indicators also need to be fully expanded. On the other hand, the evaluation methods used mainly include fuzzy comprehensive evaluation method, entropy weight method, gray clustering method, gray correlation degree method, and matter element analysis method. However, weighting and rating criteria of most methods are often determined by experience and subjective. Although the entropy weight method can determine the objective weight, it depends on a large number of representative data information, and the effect is poor when the data representation is not strong. Secondly, the general method determines the case level by comparing the case evaluation value with the level threshold value, and the difference of the disastrous situation in different cases within the same disaster level is difficult to accurately express. Yu and Shen (1997) studied the ranking method of 
different cases in the same level based on the grey clustering disaster classification model, but it is not intuitive enough..

The purpose of this paper is mainly as follows: it summarizes a comprehensive set of disaster damage assessment index system that considers the impact of various aspects, provides reference for the selection of indicators for damage assessment of different disasters, and reports indicators and contents for disaster information. The cloud modelbased evaluation method is applied to the weight determination and model construction of the disaster damage assessment, thereby objectively transforming the expert weight evaluation information into quantitative data, and based on the basis of the level evaluation criteria and the intuitive and effective determination of the level.

\section{Disaster damage assessment index system}

The disaster damage assessment is to carry out hierarchical and comprehensive management according to the losses and impacts caused by various aspects. Based on the existing research, a systematic and comprehensive disaster damage assessment index system is constructed from the aspects of disaster attribute, social impact, economic impact and natural environment impact (Table 1).

Table1. Index system of disaster damages assessment

\begin{tabular}{|c|c|c|c|}
\hline Target layer & Benchmark layer & Indicator layer & Key indicators \\
\hline \multirow{9}{*}{$\begin{array}{l}\text { Assessment index } \\
\text { system of natural } \\
\text { disaster loss }\end{array}$} & \multirow[t]{2}{*}{ Disaster properties } & Time & $\begin{array}{c}\text { Disaster duration } \\
\text { Emergency resettlement time } \\
\text { Disaster area repair time }\end{array}$ \\
\hline & & Space & Disaster coverage \\
\hline & \multirow{4}{*}{ Social impact } & Population & $\begin{array}{c}\text { Death toll } \\
\text { Missing } \\
\text { Number of people affected } \\
\text { Number of people to be resettled } \\
\text { The age structure of the affected population } \\
\text { The unemployment rate of the affected population } \\
\text { The damage rate of the affected population }\end{array}$ \\
\hline & & Building facilities & $\begin{array}{l}\text { Collapsed housing } \\
\text { Damage housing } \\
\text { Lifeline project } \\
\text { Infrastructure }\end{array}$ \\
\hline & & Agricultural losses & $\begin{array}{c}\text { Area affected } \\
\text { Disaster area } \\
\text { Failures area } \\
\text { Agricultural production output }\end{array}$ \\
\hline & & $\begin{array}{l}\text { Industrial and third } \\
\text { industrial losses }\end{array}$ & $\begin{array}{l}\text { Accumulated stagnation time } \\
\text { Due to disaster number } \\
\text { Due to disastrous bankruptcy }\end{array}$ \\
\hline & \multirow{2}{*}{ Economic influence } & \multicolumn{2}{|c|}{$\begin{array}{l}\text { Direct loss and its relative GDP ratio } \\
\text { Indirect loss and its relative GDP ratio }\end{array}$} \\
\hline & & Rescue and reconstruction & $\begin{array}{c}\text { Disaster relief put into } \\
\text { disaster area restoration and reconstruction }\end{array}$ \\
\hline & $\begin{array}{l}\text { Natural environment } \\
\text { influence }\end{array}$ & \multicolumn{2}{|c|}{$\begin{array}{c}\text { Topographic geological landform influence or repair input } \\
\text { Ecosystem influence or repair input }\end{array}$} \\
\hline
\end{tabular}


Disaster attribute is a description of the scope, duration, emergency rescue and resettlement of disaster impacts. The societal impact mainly includes the damage to human health and life caused by disasters, the destruction of houses, lifeline projects and public infrastructure, and the direct and indirect effects of industrial activities such as agriculture, industry and service industries. Economic impacts are divided into direct losses, indirect losses, and emergency rescue and reconstruction efforts. The direct loss mainly refers to the direct loss or repair cost measured by the available monetary currency caused by the disaster. The indirect loss is mainly caused by the direct loss and destruction, which will not support and circulate the future sustainable development of the disaster area and the surrounding areas. The losses caused by emergency rescue and reconstruction in the disaster area refer to the investment in the rescue and resettlement of the affected people during the disaster, as well as the various inputs of the disasterstricken areas to restore normal social order and restore production to the pre-disaster level. Ecological environmental impacts are mainly loss or pollution of water and soil resources, mineral resources, forest vegetation resources, landscape resources, biological resources, etc., changes in topographic geological features, and balanced destruction of local ecosystems. The natural ecological impact of a disaster can be understood as a loss of natural resources and a higher investment in environmental protection and ecological reconstruction.

\section{Cloud model based disaster rating evaluation model}

The weight determination method of expert evaluation information based on cloud model is proposed, and the cloud model correlation method is applicable to evaluation model construction and case level determination. This method can objectively synthesize the weight information given by all experts based on experience and reflect the fuzziness and randomness contained in subjective information.

\section{Cloud model theory}

The cloud model is an uncertainty transformation model between qualitative concept expressed by linguistic value and its quantitative numerical representation, which constitutes the uncertainty mapping between qualitative and quantitative, which is convenient for portraying the randomness and fuzziness in natural language description (Li et al., 2004; Gao et al., 2017; Li et al., 2010). Using the numerical characteristics of the cloud to reflect the overall characteristics of the concept plays an extremely important role in understanding the connotation and extension of the qualitative concept (Li et al., 2014). The cloud requires a three-dimensional feature of expected, entropy and super entropy to represent a concept in its entirety. The cloud model is the specific implementation of the cloud.

(1) According to the qualitative concept and the quantitative transformation direction, it is divided into a forward cloud model and a reverse cloud model.

(2) According to the symmetry, it is divided into a symmetric cloud model, a semicloud model, and a combined cloud model.

(3) Dimensions can be extended from one-dimensional cloud models to twodimensional or even arbitrary dimensional cloud models.

The universal distribution of normal distribution and normal membership functions lays the theoretical foundation for the universality of the normal cloud model ( $\mathrm{Li}$ and Liu, 2004). The normal cloud model is widely used in research. 


\section{Cloud model accuracy test and parameter correction}

According to the reverse cloud model, it is possible that the cloud droplet dispersion is large, so it is necessary to make an accurate check and parameter correction.

The cloud drip that describe the qualitative concept are from the normal distribution $N\left(E_{x}, E_{n}^{2}+H_{e}^{2}\right)$. It is well known from the central limit theorem that when any cloud drop $x \in\left[E_{x}-Z_{\alpha / 2} \sqrt{E_{n}^{2}+H_{e}^{2}}, E_{x}+Z_{\alpha / 2} \sqrt{E_{n}^{2}+H_{e}^{2}}\right]$ is used. The degree of certainty of the qualitative concept can be expressed by the confidence degree $1-\alpha$, where $Z_{\alpha / 2}$ is the two-sided percentile of the standard normal distribution.

The accuracy test steps are as follows: (1) Use the forward cloud model to generate several cloud drops, such as the number of clouds with $n_{1}=1000$. (2) Select the qualitative concept to determine the degree and find the value $Z_{\alpha / 2}$, if the degree of determination is $95 \%, Z_{\alpha / 2}=1.96$. (3) Calculate $\left(x<E_{x}-Z_{\alpha / 2} \sqrt{E_{n}^{2}+H_{e}^{2}}\right)$ is the mean of the cloud drop points $X_{\mathrm{L}}$ and $\left(x>E_{x}+Z_{\alpha / 2} \sqrt{E_{n}^{2}+H_{e}^{2}}\right)$ the mean value of the cloud drop points $X_{\mathrm{H}}$. When Equation 1 is met, the cloud model has higher precision, otherwise the cloud parameters need to be corrected (Xu et al., 2013; Ma et al., 2010).

$$
\begin{aligned}
& \left|\left(d-d_{0}\right) / d\right| \times 100 \% \leq 20 \% \\
& d=X_{\mathrm{H}}-X_{\mathrm{L}}, \quad d_{0}=2 Z_{\alpha / 2} \sqrt{E_{n}^{2}+H_{e}^{2}}
\end{aligned}
$$

The cloud parameter correction steps are as follows: (1) Generates $n_{1}$ cloud droplet that belongs to the confidence interval $\left[E_{x}-Z_{\alpha / 2} \sqrt{E_{n}^{2}+H_{e}^{2}}, E_{x}+Z_{\alpha / 2} \sqrt{E_{n}^{2}+H_{e}^{2}}\right]$.

Calculates the sample mean $\bar{X}$ and the variance of cloud droplets $S^{2}$. (3) According to the Bayesian theory-based correction method to calculate (Liu et al., 2008):

$$
\left\{\begin{array}{l}
E_{x}^{(1)}=\left[\frac{\bar{X}}{\left(E_{n}^{2}+H_{e}^{2}\right) / n_{1}}+\frac{E_{x}}{E_{n}^{2}}\right] /\left[\frac{1}{\left(E_{n}^{2}+H_{e}^{2}\right) / n_{1}}+\frac{1}{E_{n}^{2}}\right] \\
E_{n}^{(1)}=\sqrt{\frac{\pi}{2}} \times \sum_{i=1}^{n_{1}}\left|x_{i}-E_{x}^{(1)}\right| / n_{1} \\
H_{e}^{(1)}=\sqrt{S^{2}-\left(E_{n}^{(1)}\right)^{2}}
\end{array}\right.
$$

In Equation 2: $E_{x}^{(1)}, E_{n}^{(1)}$ and $H_{e}^{(1)}$ are the revised expectation, entropy and hyperentropy, respectively, $x_{i}$ for the $i$ cloud drops. After the correction, the new cloud model parameters are tested and modified to meet the accuracy requirement. 


\section{Cloud model based weight determination method}

The weight determination steps of the expert evaluation information based on the cloud model are as follows:

(1) Invite $n$ experts (to ensure the weight calculation results are convincing, need to invite more than 10 experts to evaluate) give the weight distribution results of $\mathrm{m}$ indicators, constitute the evaluation matrix $V=\left(V_{i j}\right)(i=1,2, \cdots, m ; j=1,2, \cdots, n)$.

(2) Using the inverse cloud algorithm without certainty, calculate the $n$ weight evaluation values of the index $i$ to obtain the weight cloud model parameters $\left(E_{x}{ }^{i}, E_{n}{ }^{i}, H_{e}{ }^{i}\right)$.

(3) Perform accurate test and parameter correction on the weight cloud model of indicator.

(4) For the weighted cloud model of the modified indicator $i$, a forward cloud algorithm is used to randomly generate $t$ (such as $t=1000$ ) cloud drops, and the weights calculated $x_{i}$ as the index $i$ corresponding to the maximum degree of cloud drop point determination $\mu_{i}\left(x_{i}\right)$.

(5) Normalize the weight calculation values of the $m$ indicators to obtain the weight vector $\Omega=\left(\omega_{1}, \omega_{2}, \mathrm{~L}, \omega_{m}\right)^{\mathrm{T}}$.

Based on the weight calculation method of the cloud model, based on the existing expert evaluation values, the expert evaluation expectation $\left(E_{x}\right)$ and the uncertainty eigenvalues $\left(E_{n}\right.$ and $H_{e}$ ) can be extracted to generate any number of evaluation values that meet the characteristics of the expert evaluation (Cloud drop). Finally calculate the weight vector, increase in the number of samples calculated by weight, and improve the credibility. As $t$ increases, the weight calculated on the basis of the cloud model will tend to the expected value of the weight cloud model, which tends to the arithmetic mean of the expert weighting of the indicator. The weight vector calculated based on the cloud model considers the randomness and ambiguity of expert evaluation, and is of great importance for the study of the uncertainty method of qualitative evaluation weight calculation.

\section{Cloud-based disaster damage assessment process}

Different from the previous research, the disaster damage assessment level is directly determined in accordance with the expert experience. This model mainly determines the disaster level scale cloud with randomness and ambiguity based on the overall situation of the case evaluation, and determines the disaster level of each case. Proceed as follows:

(1) Indicator data are normalized. In order to measure the degree of disaster loss for a single indicator, the reference ceiling for each indicator has to be selected. The historical maximum value of each indicator in the existing historical data of the evaluation object can be invoked as the index reference for the upper limit. The ratio of the raw data to the reference upper limit of the corresponding indicator is the indicator value. Set the indicator data matrix $Y=Y_{i k}$ of $p$ cases $(i=1,2, \cdots, m ; k=1,2, \cdots, p)$.

(2) Evaluation vector calculation. Calculate the disaster damage assessment value of each case to form a disaster damage assessment vector $\boldsymbol{Z}=\left(z_{1}, z_{2}, \mathrm{~L}, z_{p}\right)^{\mathrm{T}}$, where the element $z_{k}$ of the vector can be expressed as Equation 3. 


$$
z_{k}=\sum_{i=1}^{m}\left(Y_{i k} \omega_{i}\right)
$$

(3) Cloud model generation. The overall disaster cloud model for $Z$ using inverse cloud algorithm without a degree of certainty, and the accuracy test and correction are performed.

(4) High-level disaster clouds and low-level disaster cloud computing. Taking the $E_{x}$ value of the overall disaster cloud as the dividing line, the case is split into high-level and low-level cases: the case where the disaster evaluation value is greater than $E_{x}$ is a high-level case, and vice versa is a low-level case. Repeat step 3 for the disaster damage assessment values of all high-level cases to obtain a high-level disaster cloud model, and a low-level disaster cloud model.

(5) Disaster level scale clouds construction. First, based on the overall disaster situation cloud, high-level disaster situation cloud and low-level disaster situation cloud, combined with the case disaster situation, etc., the evaluation value interval of the evaluation level is established. Let the evaluation value interval of the $s$ grade be $\left[a_{s}, b_{s}\right]\left(s=1,2, \mathrm{~L}, S^{\prime}\right)$, and the cloud parameter $\left(E_{x s}, E_{n s}\right)$ is calculated according to the Equation 4 (Xu et al., 2011), $H_{e s}$ is specified according to the uncertainty of the evaluation language, and is generally regarded as 0.005 .

$$
\left\{\begin{array}{l}
E_{x s}=\left(a_{s}+b_{s}\right) / 2 \\
E_{n s}=\left(b_{s}-a_{s}\right) / 6
\end{array}\right.
$$

Secondly, the accuracy test is made on each level of the cloud. Each level of cloud constitutes a disaster level scale and generates a scale cloud map.

(6) Each case level is determined. Calculate the case disaster evaluation value and the degree of the determination of the cloud, the $k$ case Disaster damage assessment value and the second grade cloud model of the determination of $\eta_{k, s}=\exp \left(-\left(x_{k}-E_{x s}\right)^{2} / 2 E_{n s}^{\prime 2}\right)$, where $E_{n s}^{\prime}$ is expected $E_{n s}, H_{e s}$ is the variance of the normal random number. The level of the most certain degree is the case level, and the second-largest level is the level deviation of the case, reflecting the difference in the disastrous situation of different cases in the same level. For example, the case of "middle disasters and partial disasters" is more serious than the case of "middle disasters and partial disasters".

\section{Example application}

The cloud model-based disaster rating assessment model was applied to six typical storms and flood disaster damage assessments. Cases 1-3 are examples of three storms and floods that occurred in 2015 (China Meteorological Disaster Yearbook, 2016), and cases 4-6 were examples of evaluations in the standards.

According to the type of disaster and the actual situation of disaster loss, the indicators of population, building facilities, agricultural losses in social impact, and direct economic loss indicators in economic impact are selected for analysis. Due to 
the lack of comprehensive statistical data, the disaster attribute and natural environmental impact indicators have not been selected yet. Based on available disaster loss data statistics, the population indicators have the number of people affected and the number of death, which are recorded as $u_{1}$ and $u_{2}$ respectively; the building facilities index selects the number of collapsed houses, which is recorded as $u_{3}$; the agricultural loss index selects the area affected by crops, recorded at $u_{4}$; and the direct economic loss is recorded as $u_{5}$. Statistics of 6 typical storm flood disaster losses are shown in Table 2.

\section{Weight determination}

Ten experts were invited to evaluate the index weight, and the weights were calculated by the weighting method of the expert evaluation information based on the cloud model. The weight of the experts and the weight calculated based on the cloud model is shown in Table 3 .

Table 2. Statistic data of 6 rainstorm and flood disaster loss

\begin{tabular}{c|c|c|c|c|c|c}
\hline Case & Disaster details & $\begin{array}{c}\text { Number of people } \\
\text { affected (million) }\end{array}$ & $\begin{array}{c}\text { Death toll } \\
\text { (person) }\end{array}$ & $\begin{array}{c}\text { House collapse } \\
\text { (million rooms) }\end{array}$ & $\begin{array}{c}\text { Area affected by } \\
\text { crops (thousand } \\
\text { hectares) }\end{array}$ & $\begin{array}{c}\text { Direct } \\
\text { economic losses } \\
\text { (billion yuan) }\end{array}$ \\
\hline 1 & $\begin{array}{c}\text { May 18, 2015-22nd Fujian } \\
\text { Rainstorm }\end{array}$ & 29.9 & 11 & 0.28 & 34 & 30.6 \\
2 & $\begin{array}{c}\text { July 20, 2015-25th Fujian } \\
\text { Rainstorm }\end{array}$ & 41.8 & 16 & 0.27 & 21 & 40 \\
4 & $\begin{array}{c}\text { August 16, 2015-19th Sichuan } \\
\text { rainstorm }\end{array}$ & 148.1 & 30 & 0.36 & 91 & 8.8 \\
5 & $\begin{array}{c}2008.06 \text { Zhujiang River basin } \\
\text { flood }\end{array}$ & 1842.96 & 50 & 5.24 & 957.85 & 131.07 \\
6 & $\begin{array}{c}2008.06 \text { Zhujiang River basin } \\
\text { flood }\end{array}$ & 1106.3 & 36 & 1.60 & 368.9 & 84.6 \\
\hline
\end{tabular}

Table 3. Index weight expert evaluation value and cloud model calculation value Indicator weight normalized weight

\begin{tabular}{|c|c|c|c|c|c|c|c|c|c|c|c|}
\hline \multirow{2}{*}{ Index } & \multicolumn{10}{|c|}{ Weight } & \multirow{2}{*}{$\begin{array}{c}\text { Normalized } \\
\text { weights }\end{array}$} \\
\hline & Prof.1 & Prof.2 & Prof.3 & Prof.4 & Prof.5 & Prof.6 & Prof.7 & Prof.8 & Prof.9 & Prof.10 & \\
\hline$u_{1}$ & 0.12 & 0.11 & 0.13 & 0.09 & 0.11 & 0.1 & 0.15 & 0.1 & 0.11 & 0.1 & 0.1125 \\
\hline$u_{2}$ & 0.35 & 0.32 & 0.34 & 0.34 & 0.35 & 0.3 & 0.35 & 0.37 & 0.33 & 0.35 & 0.3394 \\
\hline$u_{3}$ & 0.08 & 0.1 & 0.09 & 0.12 & 0.09 & 0.12 & 0.08 & 0.08 & 0.1 & 0.1 & 0.0959 \\
\hline$u_{4}$ & 0.1 & 0.13 & 0.11 & 0.1 & 0.11 & 0.12 & 0.09 & 0.12 & 0.12 & 0.1 & 0.1100 \\
\hline$u_{5}$ & 0.35 & 0.34 & 0.33 & 0.35 & 0.34 & 0.36 & 0.33 & 0.33 & 0.34 & 0.35 & 0.3422 \\
\hline
\end{tabular}

\section{Case evaluation value and disaster situation cloud model calculation}

The disaster damage assessment values of the six cases calculated in accordance with Equation 3 were 0.1006, 0.1335, 0.1064, 0.6365, 0.3879, and 0.5304, respectively. For disaster damage assessment values of the six cases, inverse cloud algorithm (Ep.1 2) was used. After the accuracy test and parameter correction, the parameters of the overall disaster cloud model $\left(E_{x}, E_{n}, H_{e}\right)$ were $(0.3092,0.2228,0.0122)$. With the overall 
disaster cloud $E_{x}=0.3092$ as the demarcation point, six cases were divided into lowlevel cases (Cases 1-3) and high-level cases (Cases 4-6). In the same way, the high-level disaster cloud parameters and the low-level disaster cloud parameters after the accuracy test and parameter correction are: $(0.5236,0.0899,0.0258),(0.1135,0.0167,0.0054)$. Generate 1000 cloud drops for each of the three disaster clouds, and generate a cloud map in the $[0,1]$ interval as showed in Figure 1.

\section{Disaster level scale cloud computing}

It can be seen from Figure 1 that the disaster damage assessment values of the lowlevel cases are concentrated in $[0.06,0.16]$, and the closer the evaluation value is to the "low-level case disaster cloud" corresponding to 0.1135 , the closer the determination is to 1 . At the same time, the analysis of the disastrous situation in 1-3 cases found that the impact of the disaster situation was small, so the initial definition of the low-level case as a whole was a general disaster. The disaster damage assessment of high-level cases is concentrated in $[0.25,0.80]$, and the closer the evaluation value is to the "high-level case disaster cloud" corresponding to 0.5236 , the closer the determination is to 1 . The analysis of the disastrous situation in the 4-6 case found that the disaster situation had a great impact. The preliminary definition of the high-level case was a major disaster. The disaster damage assessment value of the overall disaster cloud is mainly concentrated in $[0,0.8]$, and the closer the evaluation value is to 0.3092 , the closer determination of the "total disaster cloud" is to 1 . The overall disaster situation cloud integrates the general disaster situation and major disaster situation, reflecting the average level of disaster losses. It is initially considered that the case where the evaluation value is around 0.3092 is a major disaster.

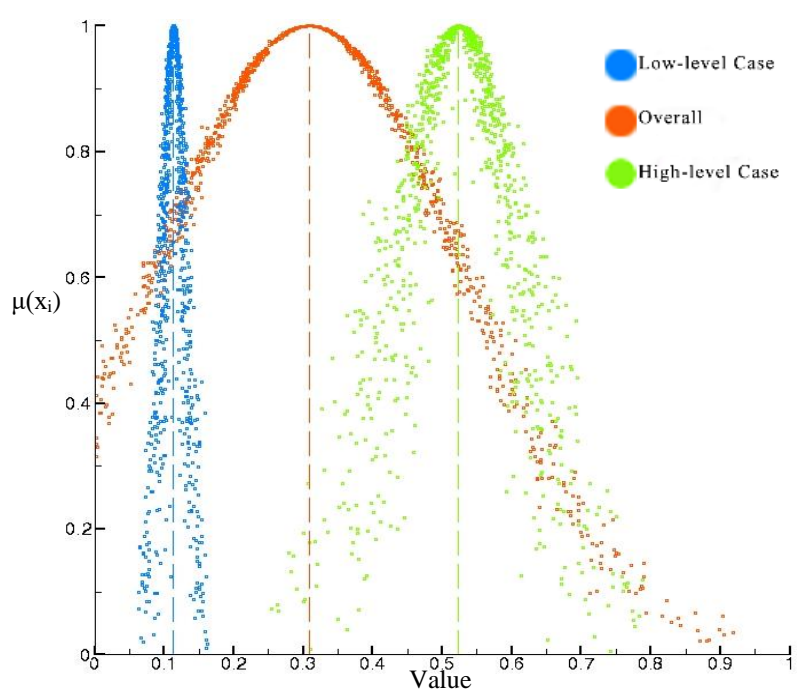

Figure 1. Each disaster cloud

According to the above analysis, considering the possibility of occurrence of disasters that are more serious than major disasters (i.e., "special major disasters"), and the construction of equidistant disaster scales, the assessment intervals for the classification of disasters are shown in Table 4. Among them, the straight line intervals $[0,0.115]$ and $[0.805,1]$ respectively indicate that the degree of certainty for "general 
disaster" and "special major disaster" is 1 when the evaluation value belongs to the interval.

Table 4. Disaster damage assessment level

\begin{tabular}{c|c|c}
\hline Interval type & Interval type & Evaluation interval \\
\hline \multirow{2}{*}{ General disasters } & Linear interval & {$[0,0.115]$} \\
& Semi-descending cloud & {$[0.115,0.345]$} \\
Large disasters & Symmetric cloud & {$[0.115,0.575]$} \\
Major disasters & Symmetric cloud & {$[0.345,0.805]$} \\
Special major disasters & Half-liter cloud & {$[0.575,0.805]$} \\
& Straight zone & {$[0.805,1]$} \\
\hline
\end{tabular}

According to the Equation 4 cloud parameters are calculated for each cloud model interval, and the Cloud model parameters $\left(E_{x}, E_{n}, H_{a}\right)$ of different disaster classes are obtained as follows: General disasters $(0.115,0.077,0.005)$; Large disasters $(0.345,0.077,0.005)$, Major Disasters $(0.575,0.077,0.005)$, particularly major Disasters $(0.805,0.077,0.005)$. Ching model accuracy test is in line with the requirements. Generate the ruler clouds as showed in Figure 2.

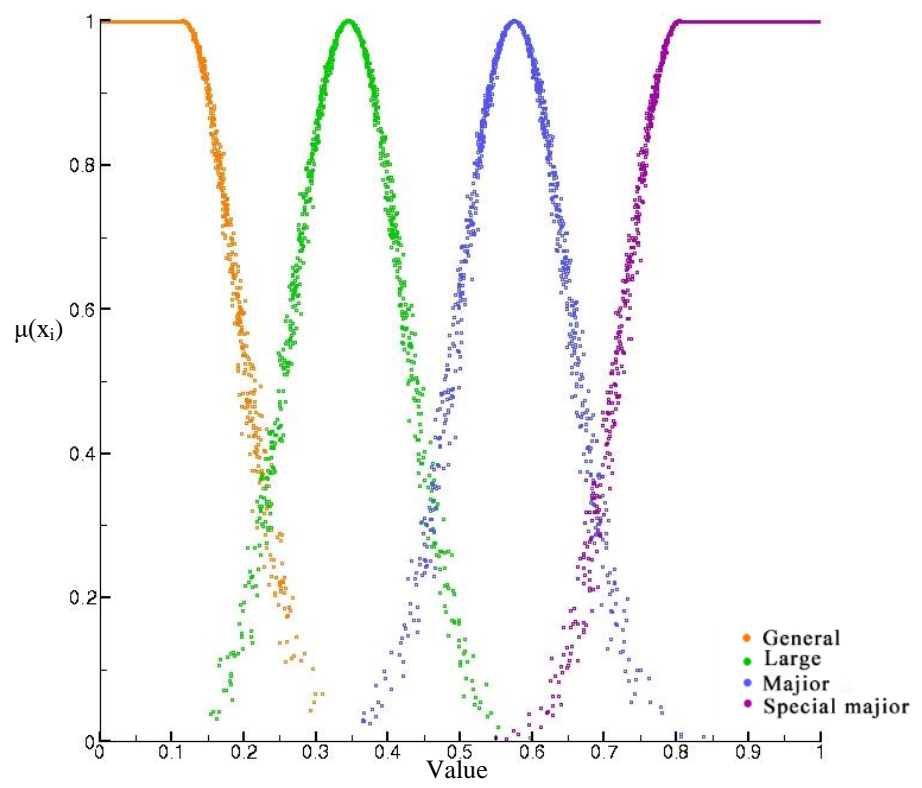

Figure 2. Disaster rating assessment ruler cloud

\section{Case rating}

Calculate the disaster damage assessment value of each case and the certain degree of cloud of each level in the scale cloud, and determine the case level according to the principle of maximum certainty. The results are presented in Table 5 and Figure 3.

It can be seen from Table 5 and Figure 3 that the most certain grades in Case 4 and Case 6 are "major disasters", and the second most important grades are "Special Major Disasters" and "Greater Disasters". In addition to simply recognizing that both are 
"significant disasters", it can be said that the disaster level of Case 4 is "significant disasters and biased towards special major disasters", and the disaster level of Case 6 is "significant disasters and biased towards larger disasters". This is in line with the actual situation: in the Case 4 indicator data, except for the "number of death" is smaller than Case 6. The other indicators are 2.2-9.4 times of Case 6. Therefore, on the whole, the disastrous situation of Case 4 is more influential than Case 6. This shows that the cloud model method can express the disaster level deviation of different cases in the same level, and intuitively reflect the difference of the disastrous situation of the same level of disaster.

Table 5. The determination of each case level and grade evaluation results

\begin{tabular}{|c|c|c|c|c|c|c|}
\hline \multirow[b]{2}{*}{ Case } & \multicolumn{4}{|c|}{ Determination } & \multirow{2}{*}{$\begin{array}{c}\text { Cloud model } \\
\text { evaluation results }\end{array}$} & \multirow[b]{2}{*}{$\begin{array}{c}\text { Cloud model } \\
\text { evaluation results }\end{array}$} \\
\hline & $\begin{array}{r}\text { General } \\
\text { disasters }\end{array}$ & $\begin{array}{r}\text { General } \\
\text { disasters }\end{array}$ & $\begin{array}{c}\text { Major } \\
\text { disasters }\end{array}$ & $\begin{array}{c}\text { Special major } \\
\text { disaster }\end{array}$ & & \\
\hline 1 & 1 & 0.0055 & 0 & 0 & General disasters & General disasters \\
\hline 2 & 0.9743 & 0.0202 & 0 & 0 & General disasters & General disasters \\
\hline 3 & 1 & 0.0173 & 0 & 0 & General disasters & General disasters \\
\hline 4 & 0 & 0.0009 & 0.7173 & 0.1706 & Major disasters & Major disasters \\
\hline 5 & 0.0005 & 0.8585 & 0.0553 & 0.0000 & General disasters & General disasters \\
\hline 6 & 0 & 0.0906 & 0.8202 & 0.0019 & Major disasters & Special major disaster \\
\hline
\end{tabular}

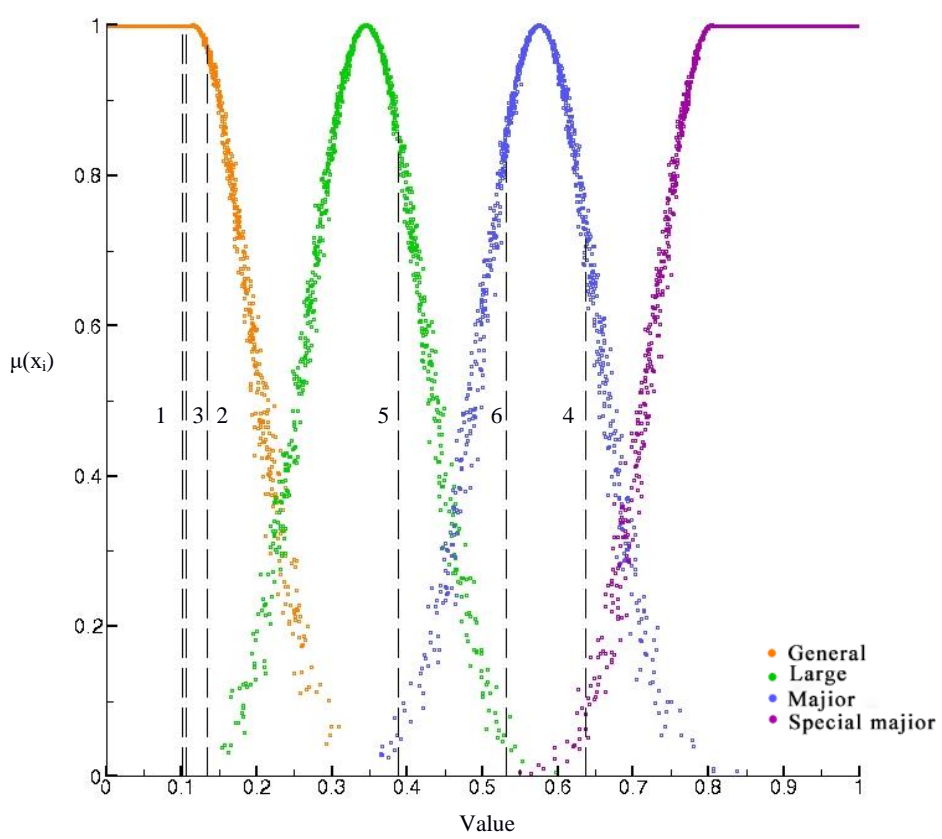

Figure 3. Case level determination chart. (The number in the figure indicates the case number, and the intersection of the dashed line with each level cloud model determines the degree of the value of the case evaluation for each level cloud)

It can be seen from Table 5 that the evaluation results of the application cloud model method are compared with the results confirmed according to the "standard": the results of Case 1-5 are the same, and the results of Case 6 are different. The consistency of the 
results of Cases 1-5 indicates that the model is applied to the applicability and rationality of storm flood and flood disaster damage assessment. Case 6 is applicable to both the identification method of the indicator system and the direct identification method ("when the death population reaches 100 people or the direct economic loss reaches 20 billion yuan, it is recognized as a special major disaster; the death population reaches 50". When there are less than 100 people or the direct economic loss reaches 10 billion yuan and less than 20 billion yuan, it is considered a "major disaster". The former conclusion is the same as the result of this paper, which is "major disaster"; the latter conclusion is different from the result of this paper, and it is "special major disaster". According to the principle of high, the conclusion that the evaluation of the Standard is adopted is "special major disaster". The model of this paper is the same as the results obtained by the identification system of the Standards, which verifies the rationality and applicability of the model. When using the direct identification method to evaluate the disaster situation, the model may not be consistent with its evaluation results (for example, Case 6 in the example in this paper), and this situation will be further analyzed in subsequent studies.

\section{Conclusion}

This paper summarizes the disaster damage assessment index system of the aspects of disaster attribute, social impact, economic impact and natural environmental influence to form a comprehensive disaster damage assessment index system that considers the impact of various aspects. It can provide reference for the selection of disaster damage assessment indicators for different disasters. The shortcoming is that the topographic geological and geomorphological impacts and ecological environmental impacts in the natural environmental impact need to be further refined according to the characteristics of disaster losses, and more specific evaluation indicators are proposed.

Based on the weight determination method of cloud model, the correlation between randomness and fuzziness was revealed, and the expert evaluation was conducted with quantification, realizes the evaluation weight of multiple experts to the uncertainty conversion of comprehensive weight data, and can fully and comprehensively consider expert opinions and common weight determination methods. More objective than comparison.

A cloud model-based disaster rating model is proposed. The model evaluation results are basically consistent with the "standard" evaluation results, which verify the rationality and applicability of the model. The model can fully consider the overall situation of the disasters studied, and reduce the subjective dependence on expert experience. The case degree is determined by the principle of maximum certainty, and the degree of disaster level of different cases of the same level is reflected by the second largest degree of certainty level. Disaster identification degree of different cases of the same level is improved based on the effective classification of the disaster level, and the general evaluation method more objective and scientific. The case level determination process reflects the ambiguity and randomness of the cloud model when the quantitative evaluation data are converted into a graded comment. However, it is found that there may be a different evaluation result between the result obtained by the direct identification method and the cloud model is used for disaster assessment in the case study, and the specific reason for the difference is still unclear, which needs further analysis and discussion in the following research. 
Acknowledgements. The study was supported by the National Natural Science Foundation of China Youth Science Foundation Project (No. 51309076), the Jiangsu General Fund(No. BK20181310), the Fundamental Research Funds for the Central Universities (No. 2014B05814), the Fundamental Research Funds for the Natural Science Foundation of Jiangsu Province(N0. BK20130849). The project was also funded by the Priority Academic Program Development of Jiangsu Higher Education Institutions (No. 3014-SYS1401).

\section{REFERENCES}

[1] Cheng, L.H., Tang, H., Zhou, T.G., Zhang, L., Zhang, M. (2011): Evaluation method of natural disaster intensity and its application: a research based on comprehensive disaster condition index. - Journal of Natural Disasters 2011(1): 46-50.

[2] China Meteorological Administration Staff (2016): China Meteorological Disaster Yearbook (2016). - Meteorological Press, Beijing.

[3] Gao, Y.Q., Chen, H.Y., Xiao, X., Xu, J. (2017): Evaluation of management modernization of large and medium-sized sluices based on cloud theory. - Journal of Economics of Water Resources 35(2): 63-68.

[4] Gong, Z.W., Hu, L. (2015): Influence factor analysis of typhoon disaster assessment. Journal of Natural Disasters 2015(1): 203-213.

[5] Li, D.Y., Liu, C.Y. (2004): Study on the Universality of the Normal Cloud Model. Engineering Science 6(8): 28-34.

[6] Li, D.Y., Liu, C.Y., Du, Y., Han, X. (2004): Artificial Intelligence with Uncertainty. Journal of Software 15(11): 001583-1594.

[7] Li, D.Y., Liu, C.Y., Gan, W. (2010): A new cognitive model: Cloud model. International Journal of Intelligent Systems 24(3): 357-375.

[8] Li, D.Y., Liu, C.W., Du, Y., Xu, J. (2014): Uncertain Artificial Intelligence. - National Defence Industry Press, Beijing.

[9] Liu, J., Deng, G.S., Na, R.S. (2008): Analysis and design of Bayesian feedback cloud model. - Systems Engineering - Theory \& Practice 28(7): 138-143.

[10] Liu, N.J., Li, Q., Sun, Z. (2017): Analysis of natural disasters in China in 2016. - Disaster Reduction in China 2017(2): 50-53.

[11] Ma, S.D., Han, L., Gong, G.H., Song, X. (2010): Target threat assessment technology based on cloud model. - Journal of Beijing University of Aeronautics and Astronautics 36(2): 150-153.

[12] Ministry of Water Resources of the People's Republic of China Staff, 2012. Flood Disaster Assessment (SL 579-2012). - China Water \& Power Press, The Beijing.

[13] Shi, L.M., Li, B., Li, Y.Y., Kong, L.W., Liu, W.P. (2017): Study on economic loss assessment and risk division of hail disaster in Xinjiang. - Journal of Glaciology and Geocryology 39(2): 299-307.

[14] Tang, Y.D., Yu, W. (2016): Disaster Economics 2. - Tsinghua University Press, Beijing.

[15] Xu, H.J., Wang, Z.Y., Su, H.Y. (2013): Dissolved gas analysis based feedback cloud entropy model for power transformer fault diagnosis. - Power System Protection and Control 2013(23): 115-119.

[16] Xu, K.H., Meng, Q., Li, K. (2011). The comprehensive evaluation of attack formations of tank element base on cloud theory. - Fire Control \& Command Control 36(10): 37-40.

[17] Yang, X.L., Zhou, J.Z., Ding, J.H., Zhang, Y.Z. (2010): Attribute recognition model for comprehensive evaluation of flood grades based on entropy method. - Yangtze River 41(12): 16-19.

[18] Yin, K.D., Wei, Q., Li, X.D. (2012). The evaluation techniques of the socio-economic loss caused by storm surge disaster. - Marine Environmental Science 31(6): 835-837.

[19] Yu, Q.D., Shen, R.F. (1997). A grading model and its application of the comprehensive situation of natural disaster. - Journal of Catastrophology 1997(3): 12-17. 